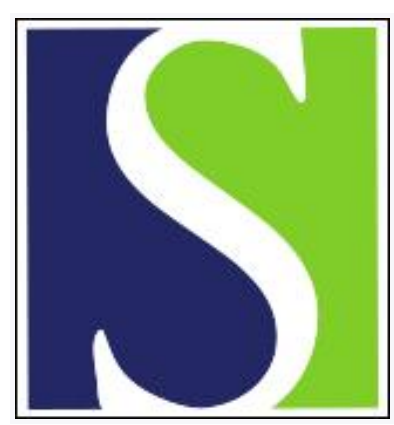

Scand J Work Environ Health 2004;30(3):173-177

https://doi.org/10.5271/sjweh.777

Issue date: Jun 2004

Expo[not-so]sure... Reflections on a Tricky Issue in musculoskeletal research.

by Mathiassen SE

Affiliation: Department of Occupational and Environmental Medicine, Lund University Hospital, SE-22185 Lund, Sweden. svenderik.mathiassen@ymed.lu.se

Refers to the following text of the Journal: $2004 ; 30(3): 179-190$

Key terms: editorial; exposure; musculoskeletal research

This article in PubMed: www.ncbi.nlm.nih.gov/pubmed/15250645

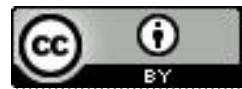




\title{
Expo[not-so]sure... Reflections on a Tricky Issue in musculoskeletal research
}

\author{
"Well," said Owl, "the customary procedure in such cases is as follows." \\ "What does Crustimoney Proseedcake mean?" said Pooh. "For I am a Bear \\ of Very Little Brain, and long words Bother me." \\ "It means the Thing to Do." \\ "As long as it means that, I don't mind," said Pooh humbly.
}

A.A. Milne (1)

Among the characters in the Hundred Acre Wood, Owl likes long, difficult words the best. While Rabbit always figures out a plan for solving a problem within 5 seconds or so, and takes for granted that everybody else agrees, Owl loves to get himself involved in long, impressive explanations of what the problem is all about. Owl knows about words like "dorsal" and "muscles", and he would have been thrilled by the prospects of increasing his vocabulary with "exposure", "agent", "mechanical", and, the most Owl'ish of them all, "musculoskeletal". Thus he would have devoured the paper by Wells et al in this issue of the Scandinavian Journal of Work, Environment \& Health (2).

Hopefully, while imbibing these new words, Owl would also notice what they stand for, since this is the issue of the paper. The authors describe a model in which the environment contains "aspects" that can potentially result in the generation of force in or on workers. While this potential force is called the "agent", the word "exposure" describes the interaction between the agent and a "target", which is a tissue in the worker that might be affected by force. Since force is transmitted through different tissues, and transformed along the route, several "internal exposure" interactions can occur. The time pattern of force(s) experienced by the worker can be estimated from a job description or, probably more correctly, from an activity record or by direct measurements.

In suggesting this model, the authors wish to clarify and standardize concepts and terms that are in general use, and occasional misuse, in musculoskeletal research. This is a commendable endeavor, since it is obviously no good if researchers use different words for similar concepts, or the same word for different concepts. In having this objective, the paper joins a vivid debate that reached its peak about 10 years ago (3-5), with occasional revivals up to date (6). At times pretty Owl'ish, this debate has concerned, for instance, whether "exposure" can be used for things happening inside the worker or only for work environment features that are there even when the worker is not. Other controversies have concerned whether the worker's activities (or postures or work technique) are intermediates in the transition of work requirements into bodily forces or are effect modifiers of that transition and whether "psychosocial" factors (a term that even Owl would have a hard time explaining) should be included in or left out of models with a biomechanical basis. Even the present model (2) could, all by itself, initiate some Owl'ish speculation, for instance, on how "exposure" can be defined as "contact between the worker and the agent from the environment", that is, the very happening of a worker meeting an agent, while, at the same time, being measured in Newtons, that is, in units of force. So, is "exposure" a configuration in/on the worker's body of forces that are latently present in the environment and are "activated" when the worker appears or is "exposure" the interactive initial process of creating these bodily forces?

In any case, in hindsight, the debate on "exposure" and related concepts might have shown, most of all, that models with different emphases can be useful for different purposes. Models serving the needs of occupational biomechanics $(2,5)$ or physiology $(4)$ may, just by doing so, not satisfy researchers in psychology or sociology, even if the common interest is work-related disorders. This is a dilemma. In 
order to be better able to study musculoskeletal disorders, representatives of different scientific disciplines develop discipline-specific models (6), but, just by doing so, they alienate themselves from a comprehensive, multidisciplinary view on the development, progression, and consequences of disorders in worklife, let alone on how to intervene against them. The present model (2) is no exception, being focused strictly on force as the causative factor and tissue damage as the outcome.

The paper by Wells et al (2) also discusses the construct of "exposure indices" (why not "exposure parameters"??), that is, numbers that describe some characteristic of the exposure time history. In order to be of any interest, an exposure index must represent available evidence or at least a sound theory linking exposure to a relevant outcome, be it tissue damage, as in the present model, or decreased performance capacity, pain, or another variable from the disparate array appearing in the literature (7). In agreement with previous papers (5), Wells et al (2) argue along the line that, while exposure is completely described through a continuous force-versus-time record, the challenge is to reduce the megabytes of data down to manageable figures that predict outcome. And, despite years of intense research, the answers to what these indicative figures would be are still, on the whole, blowing in the wind. Only a few quantitative relationships between mechanical exposure and musculoskeletal outcome have been demonstrated, preferentially in situations in which biomechanical exposure levels were substantial (8-9). But disorders are also prevalent in occupations with low exposure levels, like computer work or electronics assembly, for reasons that are subject to intense debate, not only among researchers, but also far out in the public arena.

A Rabbit'ish biomechanist maintains that there is, indeed, a biomechanical or physiological Heffalump out there. Nobody has seen it yet, but Rabbit's got a plan of how to catch it! The Eeyore'ish debater, on the other hand, states that, "as you know Pooh Bear", people live miserable lives, and those disorders, "as they call it, don't blame me", are just people's way of giving in. In his hunt for the Heffalump, Rabbit-preferring a structured approach—would turn to recent hypotheses of what might go wrong in low-level, long-term work with little variation. He would have Christopher Robin explaining to him the theory that certain low-threshold "Cinderella" motor units in a muscle are active without interruption as soon as that muscle is used and that these units eventually get hurt. Christopher Robin might even know about the current discussion of whether this stereotyped, orderly motor unit recruitment occurs in ordinary people during normal work or whether it is an exception that only appears under certain constrained conditions, and only in some individuals (10). In the latter case, situations leading to an increased risk of Cinderella recruitment might—-and now l'm just guessing, Rabbit"- have the common denominator of a loss of degrees of freedom in motor control. The loss may come about because work has to be performed under time pressure in constrained postures or with standardized movements. Degrees of freedom might also be reduced due to dysfunctional muscle fibers or altered sensory feedback from active muscles, and people may even differ- “don't ask me why, Rabbit" - with respect to their basic motor control strategies (11).

If the Heffalump looks and behaves according to these theories, Rabbit will have to locate him in worklife by means of exposure indices capturing aspects of force variation over time, rather than by indices expressing the overall force distribution. Indices in the latter category, like time-weighted averages or selected percentiles of the cumulative exposure distribution (12), have a long and strong tradition in musculoskeletal research, and they seem to survive partly just because of this historical dignity. Mechanical exposure indices representing time patterns have, indeed, been suggested in the literature, but to a less extent and with a regrettable diffuseness of the conceptual framework (13).

The lack of standardized indices for "variation" and "repetitiveness" and "static" is probably one reason why few studies have actually shown explicitly that "variation" at work is an important indicator of disorder risk, let alone how an optimal job looks in terms of the extent and kind of exposure "variation" (13). In spite of this lack of normative evidence, there seems to be general agreement among researchers 
and practitioners that "variation" is a Good Thing, and Swedish law even states that "... risks of ill-health shall be averted by job rotation, job diversification, breaks or other measures which can augment the variation at work" (14). Since the current technological and organizational trends in worklife point to more and more jobs consisting of doing similar low-level-exposure activities for prolonged periods, Rabbit should try hard to get the Heffalump into his trap. If it exists...

While modern worklife confronts musculoskeletal research with problems as to which exposure indices to use and why, even Eeyore would consider this to be a minor issue when compared with the questions of who to collect data from and when. Musculoskeletal intervention research and epidemiology has, to a large extent, been based on concepts and methods that require people to stick to their occupation and get at least the major part of their critical exposures there. However, a current trend in worklife in industrialized countries is flexibility, that is, flexible employment (people often change jobs), flexible work location (people also work at home), and flexible workhours (people work overtime close to deadlines). Since, in addition, the things that workers do in many jobs resemble what they do at home, the borders between work and leisure dissolve in terms of biomechanical exposure. Under such circumstances, it does not make sense to collect exposure data only at the workplace and claim afterwards that possible outcomes are caused by that particular job.

Even Rabbit would get slightly nervous if he realized that a logical implication is that biomechanical exposure should be assessed for an individual around the clock. He would also have to consider that it might be more relevant in an epidemiologic context to try to understand the contribution of the totality of work activities to the development of disorders, whatever these activities might be and whatever job they may come from, rather than to try to associate disorders strictly with specific occupations. This does not take the focus off Bad Work; rather it suggests viewing jobs and worktasks as more or less important contributors to a person's overall exposure. Not unlike the usual way of reasoning about the health effects of radiation from different sources, airborne pollutants, or heavy metals in food.

This approach draws attention to the issue of when to collect exposure data from a particular person and how long the collection periods should last. In musculoskeletal research, studies assessing exposure by means of observations or direct technical measurements have often collected data for short periodson the order of minutes-during what has been judged to be "normal work" (7). By nature, short measurements preclude assessment of what might be important aspects of "variation", for instance, the long-term time pattern of tasks and activities across day(s) and the exposure variability within and between these tasks and activities. Even for accessible indices, such as time-weighted averages, the 10minutes-of-normal-work strategy probably leads to biased estimates of job exposure, for instance, because data are not collected during breaks, which, according to Pooh, are the most important moments of them all. And a 10-minute strategy almost certainly leads to imprecise estimates, since exposure varies within and between days, even for tasks that appear to be very stereotyped (11).

Lack of precision has the well-known effect of reducing the probability that a comparison between two groups or conditions will be statistically significant $(11,15)$. In exposure outcome studies, imprecision can lead to biased regression results, to an extent depending on the study design (16-17). Since exposure variability within and between individuals can be expected to increase if the frame of reference is enlarged from "work" to "life", so will the demands on the size and structure of data materials. Some areas in epidemiology have a genuine tradition for analyzing and optimizing exposure assessment strategies, and understanding their implications (16-17), but musculoskeletal research still struggles with data collection and interpretation that is often based more on common sense than on statistical considerations.

Even further down the path leading to the Enchanted Place, where all things can be explained, Christopher Robin might suggest-since this is a thing that even Owl would not understand, let alone Pooh-to leave the traditional way of thinking in terms of individuals in musculoskeletal research and 
start expressing exposure in terms of what different products might cause. In an environmental context, it is nowadays an accepted approach, in some cases even mandatory, to estimate the overall life-cycle effect of a product, from birth to death, across whatever manufacturing, use and dismantling process it may pass on its way. Thus the product disseminates exposure on its way to whoever it may meet.

At least from a conceptual point of view, this idea has exciting perspectives. For instance, it complies better with the frame of reference used by managers and production planners than does an individualoriented epidemiologic approach based on medical science. It also offers a context for investigating the exposure effects of initiatives that cross borders between companies, such as outsourcing and supply chain management. In a global economy, a product life-cycle perspective on biomechanical exposures may thus be a tool for surveying fairness: it will show if an industry solves its own musculoskeletal problems by exporting the critical jobs somewhere else. And when Christopher Robin and his friends eventually meet at the Enchanted Place, the world may agree on a system for "mechanical exposure allowance trading" between and within countries, inspired by the Kyoto protocol that regulates global greenhouse gas emissions.

Well, back in the real world, the definition and assessment of "exposure" in musculoskeletal research are, indeed, Tricky Issues, even on a Fine Day. On one of those, all the friends in the Hundred Acre Wood set out to discover the North Pole. First came the leader Christopher Robin, right after him resolute Rabbit, then fearful Piglet and thoughtful Pooh, practical Kanga with bouncy Roo in her pocket, then intellectual Owl and gloomy Eeyore, and at the end a long line of Rabbit's friends and relations. Not that any of them really knew what the North Pole should look like, but eventually, after an eventful Expedition, Pooh found a Pole that they decided was the one they were looking for. Then they all went home again, and Pooh had a little something to revive himself.

\footnotetext{
"We are all going on an Expedition," said Christopher Robin, as he got up and brushed himself. "Thank you, Pooh."

"Going on an Expotition?" said Pooh eagerly. "I don't think l've ever been on one of those. Where are we going on this Expotition?"

"Expedition, silly old Bear. It's got an ' $x$ ' in it."

"Oh!" said Pooh. "I know." But he didn't really.
}

AA Milne (1)

\section{References}

1. Milne AA. Winnie-the-Pooh. London: Methuen \& Co Ltd; 1926.

2. Wells RP, Van Eerd D, Hägg G. Mechanical exposure concepts using force as an agent. Scand J Work Environ Health 2004;30:179-90.

3. Hagberg M. Exposure variables in ergonomic epidemiology. Am J Ind Med 1992;21:91-100.

4. Armstrong TJ, Buckle P, Fine LJ, Hagberg M, Jonsson B, Kilbom Å, et al. A conceptual model for work-related neck and upper-limb musculoskeletal disorders. Scand J Work Environ Health 1993;19:73-84.

5. Winkel J, Mathiassen SE. Assessment of physical work load in epidemiologic studies: concepts, issues and operational considerations. Ergonomics 1994;37:979-88.

6. Marras WS. State-of-the-art research perspectives on musculoskeletal disorder causation and control: the need for an intergraded understanding of risk. J Electromyogr Kinesiol 2004;14:1-5.

7. Punnett L, Wegman DH. Work-related musculoskeletal disorders: the epidemiologic evidence and the debate. J Electromyogr Kinesiol 2004;14:13-23.

8. Norman R, Wells R, Neumann P, Frank J, Shannon H, Kerr M, et al. A comparison of peak vs cumulative physical work exposure risk factors for the reporting of low back pain in the automotive industry. Clin Biomech 1998;13:561-73.

9. Svendsen SW, Bonde JP, Mathiassen SE, Steengaard-Pedersen K, Frich LH. Work-related shoulder disorders: quantitative exposure-response relationships with reference to arm posture. Occup Environ Med. In Press.

10. Fallentin N. Motor unit recruitment in relation to genesis of muscle pain (Cinderella hypothesis). In: Johansson H, Windhorts U, Djupsjöbacka M, Passatore M, editors. Chronic work-related myalgia. Gävle: Gävle University Press; 2003. p 133-40.

11. Mathiassen SE, Möller T, Forsman M. Variability in mechanical exposure within and between individuals performing a highly constrained industrial work task. Ergonomics 2003;46:800-24.

12. Jonsson B. Measurement and evalution of local muscular strain in the shoulder during constrained work. J Hum Ergol 
1982;11:73-88.

13. Mathiassen SE, Christmansson M. Variation and Autonomy. In: Delleman N, Haslegrave C, Chaffin D, editors. Working postures and movements- tools for evaluation and engineering. London: Taylor \& Francis. In press.

14. Swedish National Board of Occupational Safety and Health. Ergonomics for the prevention of musculoskeletal disorders. Stockholm: Swedish National Board of Occupational Safety and Health; 1998. AFS 1998:1.

15. Mathiassen SE, Burdorf A, van der Beek AJ. Statistical power and measurement allocation in ergonomic intervention studies assessing upper trapezius EMG amplitude: a case study of assembly work. J Electromyogr Kinesiol 2002;12:2739.

16. Reeves GK, Cox DR, Darby SC, Whitley E. Some aspects of measurement error in explanatory variables for continuous and binary regression models. Stat Med 1998;17:2157-77.

17. Loomis D, Kromhout H. Exposure variability: concepts and applications in occupational epidemiology. Am J Ind Med 2004;45:113-22.

\section{Svend Erik Mathiassen}

Department of Occupational and Environmental Medicine

Lund University Hospital, SE-22185 Lund, Sweden

[svenderik.mathiassen@ymed.Iu.se] 


\section{Scandinavian Journal of Work, Environment \& Health}

The Scandinavian Journal of Work, Environment \& Health is an international scientific periodical which began publication in 1975. The Journal appears 6 times a year, at the end of February, April, June, August, October, and December. In addition 1 to 3 self-financed supplements on specific topics are generally published annually.

The circulation of the Journal is worldwide. By the end of 2003, the total distribution was about 1100 copies to approximately 45 countries on 5 continents. Most of the subscriptions came from the United States (179), Finland (92), The Netherlands (82), Italy (61), Canada (52), Germany and Great Britain (48), Norway (46), Sweden (40), Spain (30), France (28), Australia and Japan (27), and Denmark (24).

The Journal is open to all authors without regard to nationality. In 2003, the number of manuscripts submitted for publication in a regular issue was 157. In volume 29, the first author of the 80 published articles (supplements included) was from Finland (16), Sweden (13), Denmark (11), The Netherlands and the United States (9), Norway (6), Canada and the United Kingdom (5), Italy (2), France (1), Germany (1), Czech Republic (1), and Iceland (1).

The acceptance rate of the 157 articles submitted in 2003 was $26 \%$ by the end of March 2003; at that time the decision was still pending for 24 of the manuscripts.

In a peer-review process, 1 to 4 referees independently evaluate the scientific quality of the submitted manuscripts. The Journal uses a double-blind peerreview system.

The elapsed time from submission to publication for the articles published in 2003 averaged 9 months. A decision of acceptance of a manuscript was reached in 1 to 3 months (average 7 weeks).

The Journal is indexed or abstracted in Current Contents, the Science Citation Index, Biological Abstracts, Excerpta Medica, CISDOCE HSELINE, TZXLIRE, NIOSHTIC, etc.

For the latest year available, 2002, the impact factor of the Journal was 1.848 . 